\title{
Between two walls: Modeling the adsorption behavior of $\beta$-glucosidase A on bare and SAM-functionalised gold surfaces
}

Nicolas Bourassin ${ }^{1,2}$, Florent Barbault ${ }^{3}$, Marc Baaden $^{1,2}$, and Sophie Sacquin-Mora ${ }^{1,2 *}$

${ }^{1}$ CNRS, Université de Paris, UPR 9080, Laboratoire de Biochimie Théorique,

13 rue Pierre et Marie Curie, 75005 Paris, France

2Institut de Biologie Physico-Chimique-Fondation Edmond de Rotschild,

PSL Research University, Paris, France

3Université de Paris, ITODYS, CNRS, F-75006, Paris, France

*Corresponding author e-mail: sacquin@ibpc.fr

Running title : Adsorption of $\beta$-glucosidase A on bare and SAM covered gold surfaces

Keywords: Molecular Dynamics, protein mechanics, protein adsorption, coarse-grain simulations

A preliminary version of this work was deposited in bioRxiv, doi: https://doi.org/

$10.1101 / 2021.07 .02 .450859$ 


\begin{abstract}
The efficient immobilization of enzymes on surfaces remains a complex but central issue in the biomaterials field, which requires us to understand this process at the atomic level. Using a multi-scale approach combining all-atom molecular dynamics and coarsegrain Brownian dynamics simulations, we investigated the adsorption behavior of $\beta$ glucosidase A ( $\beta \mathrm{GA})$ on bare and SAM-functionalized gold surfaces. We monitored the enzyme position and orientation during the MD trajectories, and measured the contacts it forms with both surfaces. While the adsorption process has little impact on the protein conformation, it can nonetheless perturb its mechanical properties and catalytic activity. Our results show that compared to the SAM-functionalized surface, the adsorption of $\beta \mathrm{GA}$ on bare gold is more stable, but also less specific, and more likely to disrupt the enzyme's function. This observation emphasizes the fact that the structural organization of proteins at the solid interface is a keypoint when designing devices based on enzyme immobilization, as one must find an acceptable stability-activity trade-off.
\end{abstract}




\section{Introduction}

The immobilization of enzymes on solid supports has attracted growing interest in the biomaterials field over the last forty years, ${ }^{1-2}$ as this phenomenon plays a central part in numerous applications, ${ }^{3-4}$ such as biosensors, ${ }^{5-6}$ biofuel cells ${ }^{7-9}$ or biomedical devices ${ }^{10-11}$. When investigating the interaction between an enzyme and a solid surface, two key issues that should be addressed are the stability of the protein/surface interface, and the protein orientation on this surface. Ensuring a correct protein orientation is essential for example in bioelectrocatalysis devices, where it will enable a direct electron transfer between the adsorbed redox enzyme and the electrode. ${ }^{12-15}$ In addition, one must make sure that the enzyme active site remains accessible after immobilization. ${ }^{16}$ This can be achieved either through targeted chemical linkage between the protein and the surface, ${ }^{17-19}$ or via the adequate functionalization of the surface, for exemple with self-assembled monolayer (SAMs), in order to adapt its charge and physico-chemical properties to a specific protein..$^{20-23}$ One must also pay attention to the conservation of the adsorbed protein's structure and dynamics, as perturbations in the protein conformation ${ }^{24-26}$ or internal mobility ${ }^{27}$ are likely to result in a dramatic decrease of the catalytic activity. Altogether, the molecular mechanisms taking place upon enzyme immobilization are not well understood. While most experiments on immobilized proteins, either via a covalent ${ }^{28-29}$ or non-covalent ${ }^{30-32}$ strategy, report a decrease in their catalytic activity, sometimes enzyme immobilization can also result in an important increase of the catalytic performance. ${ }^{33}$

Numerous enzyme immobilization strategies have been developed, that involve simple adsorption via electrostatic or van der Waals interactions, the use of porous materials, 
crosslinking, or multipoint-covalent attachment, ${ }^{33-35}$ and many experimental approaches are now available to investigate protein immobilization on solid surfaces, including atomic force microscopy, mass spectrometry and spectroscopic methods. ${ }^{36-37}$ Still, experimental techniques fail to provide us structural information regarding the proteinsurface interaction at the atomistic level. As a consequence, computational models have been playing an increasingly important part, as they can bring greater hindsight on the chemical and biological processes taking place at the bio-nano interface. The last decade has seen a wealth of methodological developments, in particular with multiscale approaches combining all-atom and coarse-grained representations. ${ }^{38-41}$ Molecular simulations techniques are now a powerful tool in the biomaterials field, ${ }^{42-45}$ as they enable us to model various surface types ${ }^{22,} 46$ (such as metals, oxides, carbon or silicabased of functionalized with SAMs), and investigate how the surface structure ${ }^{47}$ and chemical properties can impact the orientation, conformation and activity of immobilized proteins.

$\beta$-Glucosidase $A(\beta G A)$ is an enzyme which cleaves $\beta$-glucosidic linkages in disaccharide or glucose-substituted molecules, and plays a fundamental role in processes such as cellulose degradation. ${ }^{48}$ The enzyme is extensively used by the industry for the production of ethanol for biofuel, and the optimization of its function and reusability is thus of practical concern. ${ }^{49-53}$ Experimental studies on immobilized $\beta G A$, using covalent 28,50 or non-covalent $51-52$ binding strategies, show that the immobilized enzyme presents an enhanced thermal stability and $\mathrm{pH}$ tolerance, but a reduced catalytic activity compared to the free enzyme. This decrease in the enzymatic function after immobilization can be due to several factors, such as a reduced 
accessibility of the substrate to the catalytic active site, or changes in the enzyme conformation and rigidity.

In this work, we combine all-atom Molecular Dynamics (MD) and coarse-grain Brownian Dynamics (BD) simulations to investigate the adsorption behavior of $\beta \mathrm{GA}$, namely its orientation with regard to the solid surfaces and the impact of adsorption on its structure and dynamics, when it is confined between a bare and a hexanol-thiolSAM-functionalized gold surface. While the analysis of the MD trajectories shows that $\beta G A$ will preferentially adsorb on the bare gold surface, the coarse-grain calculations suggest that this stronger protein-surface interaction is also more likely to perturb the enzyme mechanical properties, which in turn might have some repercussion on its function. Altogether, our results highlight the fact that when setting up a protein immobilization strategy, one must achieve a delicate balance between the enzyme stability and its catalytic activity.

\section{Material and Methods}

\section{All-atom Molecular Dynamics simulations}

Simulation setup The 3D coordinates of the $\beta \mathrm{GA}$ were extracted from the protein data bank under the accession code 3ahx, which corresponds to the X-ray structure of bacterial $\beta$ GA from Clostridium cellulovorans. ${ }^{48}$ Molecular dynamics simulations (MD) for the protein/surface system were realized with the Amber $16^{54-55}$ software suite under periodic boundary conditions with the Particle Mesh Ewald (PME) method.56 The enzyme's net charge is $-13 \mathrm{e}$, and $13 \mathrm{Na}^{+}$ions were randomly placed in the simulation box to neutralize the system. We then used the center of mass of the $\beta$ GA heavy atoms as the center of the referential for calculating the enzyme's dipole moment, ${ }^{57}$ with the $\mathrm{x}$ 
Figure 1: Initial position and orientation of $\beta G A$ in the z0 trajectory. The five additional starting orientations were obtained by rotating the enzyme around the $x$ and $z$ axes. Figures 1, 4 and $6 a$ (and SI-1, SI-2, SI-3 and SI-5d) were prepared using Visual Molecular Dynamics.
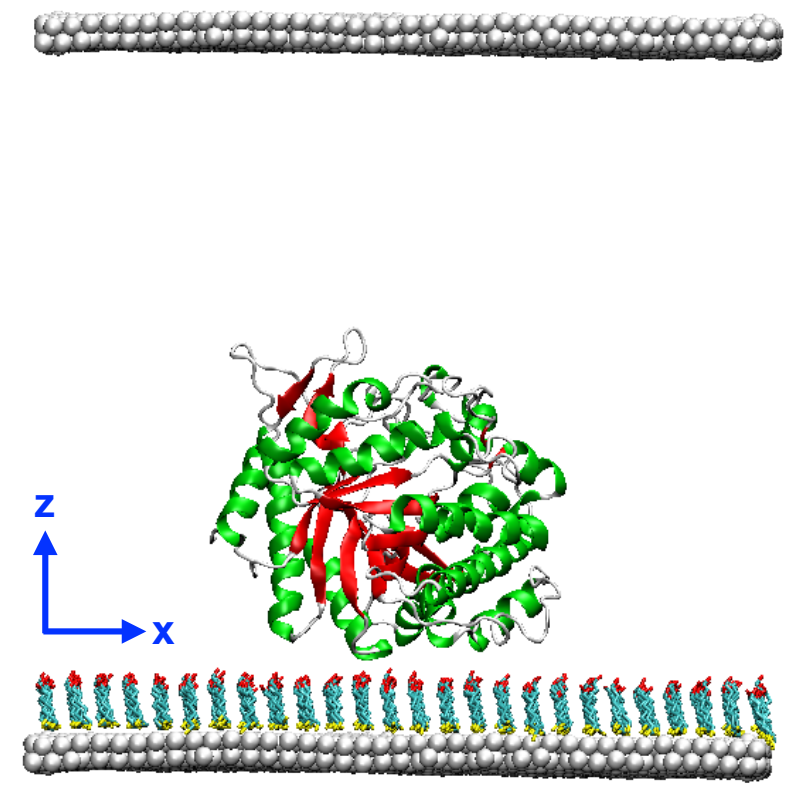

and $y$ axes being parallel to the solid surfaces, and the $\mathrm{z}$ axis perpendicular to it (see Figure 1). $\beta$ GA has a weak dipole moment (of around 20D) and its electrostatic surface (shown in Figure SI-1) does not present any large positively or negatively charged patch. As a consequence, and unlike proteins with a large dipole moment such as hydrogenases ${ }^{12}$ or bilirubin oxidases ${ }^{58}$, it is not possible to infer its orientation on a polar surface from its electrostatic properties. To explore how the starting protein orientation will impact its adsorption on the solid surfaces, six different orientations were generated like a dice, by rotating the protein around the $\mathrm{x}$ and $\mathrm{z}$ vectors (shown in Figure 1), so that each starting orientation shows a different face of the enzyme toward the functionalized surface, and the enzyme is initially placed in the simulation box with its center of mass $3.2 \mathrm{~nm}$ above the SAM-functionalized surface. The six starting orientations have been labelled as z0, z90, x0, x90, x180 and x270 (and are shown in Figure SI-2), and the corresponding simulations will be referred to as the confined 
trajectories for the rest of the manuscript, as the displacement of the enzyme in the zdirection is limited by the solid surfaces.

Consideration of the gold surface functionalized with a 6-mercapto-1-hexanol SAM were reproduced from previous works. ${ }^{59-60}$ Starting from this last validated model, the surface was extended to a square of $132 \mathrm{~nm}^{2}$ in order to let enough room for the protein to make translations and rotations during simulations. To facilitate adsorption analyses, the functionalized gold surface is placed on the $\mathrm{xOy}$ plane and periodic conditions are set to provide a uniform surface on the xOy plane. Atomic distances between real and image space is of $12.5 \mathrm{~nm}$ along the $\mathrm{z}$ direction so that the protein is placed in a rectangular simulation box, between two homogenous solid surfaces: a SAM-OHfunctionalized one below and a solely $\mathrm{Au}\{111\}$ surface at $12 \mathrm{~nm}$ above. The six starting systems were then solvated with TIP3P water molecules. ${ }^{61}$ The ff14SB force-field 62 was chosen for the protein while the functionalized gold surface was treated with a previously validated set of parameters. ${ }^{60} \mathrm{~A}$ technical note on this parameters choice is available as supplementary information. The final system comprises around 7000 atoms for the enzyme, 16500 atoms for the SAM-functionalized gold surface and 45 000 water molecules.

The six systems were subjected to the same simulation protocol. First, a two-step minimization of the solvent has been carried out with the surface and the alpha carbons of the protein restrained by a harmonic potential of 10 and $1 \mathrm{kcal} . \mathrm{mol}^{-1} . \AA^{-2}$ respectively. Then, a final optimization without restraints was performed until a gradient convergence lower than $10^{-5} \mathrm{kcal} \cdot \mathrm{mol}^{-1} . \AA^{-1}$ was achieved. The systems were then heated to $300 \mathrm{~K}$ with a first 100 ps step in the NVT ensemble to $100 \mathrm{~K}$, followed by 100 ps in the NTP ensemble to reach $300 \mathrm{~K}$. In order to avoid premature surface adsorption 
during this heating phase, $10 \mathrm{kcal} . \mathrm{mol}^{-1} . \AA^{-2}$ harmonic restraints on the solute (surface and protein alpha carbons) were added to the systems leading, sometimes, to some undesired vacuum bubbles. To remove them, a supplemental 500 ps NTP equilibration has been performed at $300 \mathrm{~K}$ where the surface and protein were kept frozen. During this stage the water density reaches an equilibrated value of 1.07 by adjusting its periodic volume in the z-direction so that the distance between the surface in the real and image spaces is around $12.0 \mathrm{~nm}$.

The six confined MD simulations were performed for $100 \mathrm{~ns}$ each in the NVT ensemble, which is classically chosen for solid interface investigations. ${ }^{32,58,63}$ During the MD production, positions of $\mathrm{Au}, \mathrm{S}$ and its first covalent carbon atom were kept restrained (with a harmonic restraint of $10 \mathrm{kcal}^{\mathrm{mol}} \mathrm{m}^{-1}$ ) so that distance and tilt angle, determined previously at the QM level,59 were respected in the MD simulations. The heating, equilibration and production parts were performed with 2 fs integration steps. 1000 frames (corresponding to one frame every $0.1 \mathrm{~ns}$ ) were saved for each of the six confined trajectories.

In addition, a MD simulation of $\beta$ GA in solution was performed with AMBER using a similar protocol. A two-steps minimization was undertaken with a first optimization of the solvent while the solute is restrained with harmonic restraints of $10 \mathrm{kcal} \cdot \mathrm{mol}^{-1}$. These restraints are removed for the second minimization until energy convergence. A two-step heating followed, with first 50 ps in the NVT ensemble to reach $100 \mathrm{~K}$, and then $100 \mathrm{ps}$ in the NPT ensemble to reach $300 \mathrm{~K}$. This last stage was followed by a solvent density equilibration step of $500 \mathrm{ps}$ in the NTP ensemble at $300 \mathrm{~K}$. Finally, a production run of $485 \mathrm{~ns}$ was performed in the NPT ensemble. The properties of $\beta \mathrm{GA}$ during this simulation, which we will refer to as the bulk trajectory, were used as a 
Table 1: Representative structures from the bulk and confined MD trajectories that were selected for mechanical investigation after clustering.

\begin{tabular}{|c|c|c|c}
\hline Trajectory & $\begin{array}{c}\text { Clustering } \\
\text { cutoff }(\mathbf{A})\end{array}$ & $\begin{array}{c}\text { Position of the selected frame } \\
(\mathbf{1 0 0 0} \text { frames trajectory) }\end{array}$ & $\begin{array}{c}\text { \% of trajectory } \\
\text { representation }\end{array}$ \\
\hline Bulk & 0.85 & 360 & $99.7 \%$ \\
\hline $\mathbf{z 0}$ & 0.73 & 118 & $19.8 \%$ \\
& & 461 & $43.4 \%$ \\
\hline $\mathbf{z 1 8 0}$ & 0.73 & 814 & $29.8 \%$ \\
\hline & & 19 & $2.4 \%$ \\
\hline $\mathbf{x 0}$ & & 186 & $93.0 \%$ \\
\hline $\mathbf{x 9 0}$ & 0.73 & 990 & $1.8 \%$ \\
\hline $\mathbf{x 1 8 0}$ & 0.73 & 270 & $97.6 \%$ \\
\hline & & 265 & $61.6 \%$ \\
\hline $\mathbf{x 2 7 0}$ & 0.73 & 913 & $37.9 \%$ \\
\hline
\end{tabular}

reference when assessing the impact of surface adsorption on the protein. Again, we used 2 fs integration steps, and 1000 frames (corresponding this time to one frame every $0.485 \mathrm{~ns})$ were saved for the bulk trajectory.

Analysis The gmx_cluster algorithm from the Gromacs (2018.8) suite ${ }^{64}$ was used to extract statistically representative structures for each trajectory over the simulation production period. The clustering cutoff was modulated in order to obtain between one and three clusters for each trajectory (depending on the amplitude of the conformational changes undergone by the enzyme during the MD simulation), and for each cluster, the most representative frame was kept. Each frame represents a cluster that must comprise at least ten members ( $1 \%$ of the total trajectory). And for a given trajectory, the 
ensemble of the selected structures must represent at least $90 \%$ of this trajectory. Alltogether, for the seven trajectories (bulk and confined) these criterions lead to the selection of 14 frames that are listed in Table1. All the structures remain very close to the experimental reference structure, with a backbone rmsd comprised between 1 and 2 $\AA$. These structures (shown in Figure SI-3) were then used to investigate the mechanical changes undergone by $\beta \mathrm{GA}$ during the simulations.

\section{Coarse-grain Brownian Dynamics simulations}

Rigidity profile of a protein Coarse-grained Brownian Dynamics (BD) simulations were run using the ProPHet (Probing Protein Heterogeneity, available online at https:// bioserv.rpbs.univ-paris-diderot.fr/services/ProPHet/) program ${ }^{65-67}$. In this approach, the protein is represented using an elastic network model (ENM). Unlike most common coarse-grained models where each residue is described by a single pseudoatom, ${ }^{68}$ ProPHet uses a more detailed representation ${ }^{69}$ that involves up to 3 pseudoatoms per residue and enables different amino acids to be distinguished. Pseudoatoms closer than the cutoff parameter $R_{c}=9 \AA$ are joined by Gaussian springs which all have identical spring constants of $\gamma_{\text {struct }}=0.42 \mathrm{~N} \cdot \mathrm{m}^{-1}\left(0.6 \mathrm{kcal} . \mathrm{mol}^{-1} . \AA^{-2}\right)$. The springs are taken to be relaxed for the initial conformation of the protein. The simulations use an implicit solvent representation via the diffusion and random displacement terms in the equation of motion, ${ }^{70}$ and hydrodynamic interactions are included through the diffusion tensor. ${ }^{71}$

Mechanical properties are obtained from 200,000 BD steps at an interval of $10 \mathrm{fs}$ and a temperature of $300 \mathrm{~K}$. The simulations lead to deformations of roughly $1.5 \AA$ rootmean-square deviation with respect to the protein starting conformation (which - by construction - corresponds to the system's equilibrium state). The trajectories are 
analyzed in terms of the fluctuations of the mean distance between each pseudoatom belonging to a given amino acid and the pseudoatoms belonging to the remaining residues of the protein. The inverse of these fluctuations yields an effective force constant $k_{i}$ describing the ease of moving a pseudoatom with respect to the overall protein structure.

$$
k_{i}=\frac{3 k_{B} T}{\left\langle\left(d_{i}-\left\langle d_{i}\right\rangle_{\operatorname{sim}}\right)^{2}\right\rangle_{\operatorname{sim}}}
$$

where \langle\rangle$_{\text {sim }}$ denotes an average taken over the whole simulation and $d_{i}=\left\langle d_{i j}\right\rangle_{j *}$ is the average distance from particle $i$ to the other particles $j$ in the protein (the sum over $j^{*}$ implies the exclusion of the pseudoatoms belonging to residue $i$ ). The distance between the $\mathrm{C}_{\alpha}$ pseudoatom of residue $i$ and the $\mathrm{C}_{\alpha}$ pseudoatoms of the adjacent residues $i-1$ and $i+1$ are excluded since the corresponding distances are virtually constant. The force constant for each residue $k$ is the average of the force constants for all its constituent pseudo atoms $i$. We will use the term rigidity profile to describe the ordered set of force constants for all the residues of the protein.

\section{Results and discussion}

\section{B-Glucosidase position in the simulation cell}

The distance between the enzyme center of mass and the SAM-OH surface during the confined trajectories is shown in Figure 2. While all confined trajectories start with $\beta \mathrm{GA}$ positioned close to the SAM functionalized surface, the enzyme remains adsorbed on the SAM in only two cases out of six (trajectories $\mathrm{x} 0$ and $\mathrm{z} 0$ ). For the remaining trajectories, $\beta \mathrm{GA}$ moves away from the lower, SAM-OH covered, surface within the first half (50 ns) of the simulation, and will either remain in an unbound state (traj. 
Figure 2: Distance between the SAM surface and the $\beta G A$ center of mass as a function of time for the six confined MD simulations.

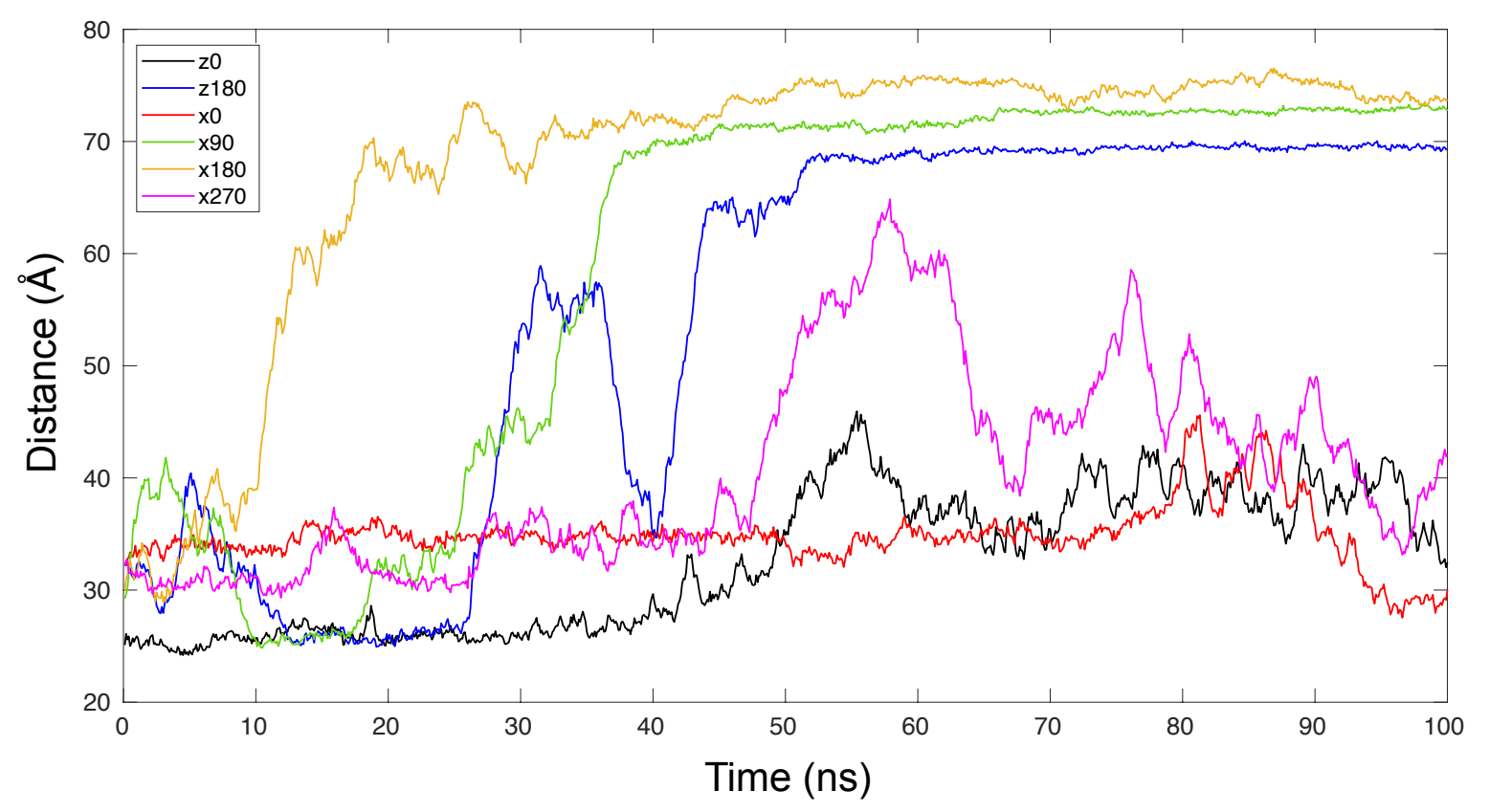

$\mathrm{x} 270$ ) or eventually bind to the bare gold surface (traj. z180, x90 and x180). At this 100

ns timescale, the enzyme adsorption on bare gold appears to be significantly more stable than on the SAM-OH surface, as no detaching event was observed in any of these three simulations for the remaining time of the trajectory. This observation can be related to the interaction energies between the enzyme and the two solid surfaces which are shown on Figure SI-4. The energy values were obtained with the NAMDEnergy plugin ${ }^{72}$ and correspond to non-bonded van der Waals and electrostatic terms. As the gold atoms are not charged,59-60 the interaction energy between $\beta \mathrm{GA}$ and the bare gold surface is entirely due to the van der Waals energy term. For the polar SAM-OH surface, van der Waals interactions account for roughly $10 \%$ of the interaction energy, while the rest is due to the electrostatic interaction term. The observed energy values are significantly more favorable for the protein-bare gold interaction (down to $-400 \mathrm{kcal}^{\mathrm{mol}}{ }^{-1}$ ) as compared to the protein-SAM-OH interaction (down to -150 kcal.mol-1), thus 
accounting for the increased stability of $\beta \mathrm{GA}$ adsorbed on gold. Interestingly, these values are agreement with those obtained in earlier simulation work on proteins adsorbed on $\mathrm{SAMs}^{32,58,73}$ or bare-gold surfaces. ${ }^{63,74-76}$ Some studies using different force fields such as CHARMM77-78 and OPLS79-80 for the proteins and SAMS, or GolP81 and coarse-grain models ${ }^{82-83}$ for the gold atoms, thus showing the robustness of molecular simulations approaches for the investigation of protein-surface interactions. These results also concur with earlier experimental work showing the preferential adsorption of proteins on apolar (here the bare gold) substrates compared to polar (SAM-OH covered gold) substrates. ${ }^{84}$

\section{B-Glucosidase orientation and contacts with the surfaces}

$\beta G A$ presents a small dipole moment (roughly 20D), and its norm and orientation within the protein structure are very stable during all the simulations that we carried out (see Figure SI-5 for the distribution of the dipole moment orientation with regard to the $\beta$ GA structure along time). Therefore we could use the tilt angle $\theta$ formed by the dipole moment orientation vector with regard to the SAM-covered surface plane to monitor the enzyme's orientation. In addition, the enzyme's rotation around its dipole moment (twist angle, $\varphi$ ) was measured by following the vector formed by the $\mathrm{C} \alpha$ atoms of residues Ile119 and Asn353, as it remains perpendicular to the dipole moment over time (see Figure SI-5c). The distribution of the tilt and twist angles along time for the six confined trajectories is shown in Figure 3. All trajectories present a different initial $(\varphi$, $\theta$ ) orientation. Trajectories $\mathrm{z} 180, \mathrm{x} 90$ and $\mathrm{x} 180$, where the enzyme binds to the bare gold surface, cover different parts of the orientational space. On the other hand, trajectories $\mathrm{z} 0, \mathrm{x} 0$ and $\mathrm{x} 270$, where the enzyme only binds to the SAM-functionalized 
Figure 3: Distribution of the twist $(\varphi)$ and tilt $(\theta)$ angles during the six confined $M D$ simulations. The color code is the same as in figure 2. The red and magenta circles indicate the initial dipole moment orientations for trajectories $x 0$ and $x 270$ respectively, and the black arrows highlight the evolution of the dipole moment orientation along time for these two trajectories.

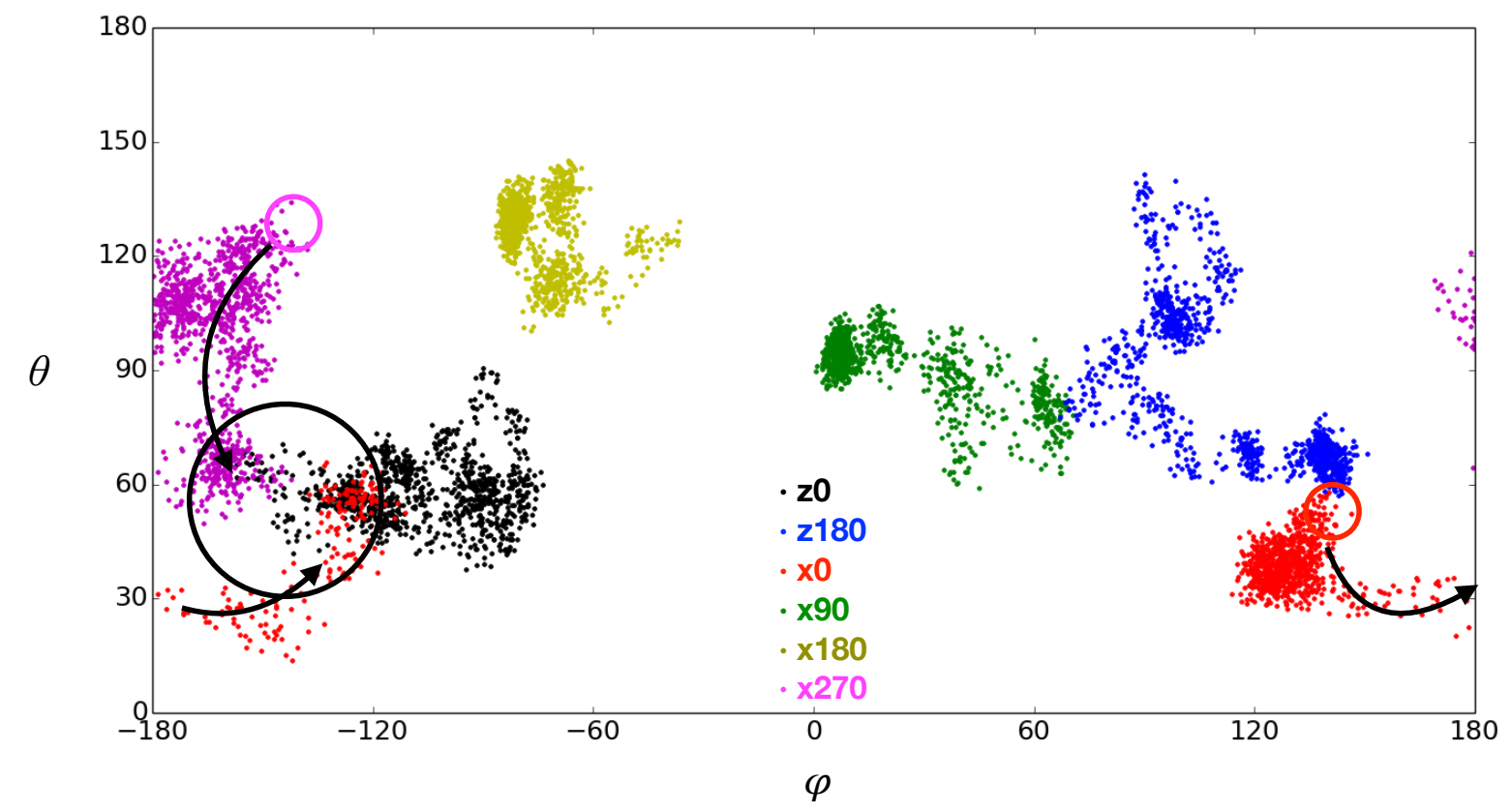

surface, seem to converge toward the same area of the graph (highlighted by a black circle in Figure 3). This observation suggests a preferential orientation of $\beta G A$ on the SAM covered surface, while the stronger (in terms of interaction energy) binding of the enzyme of the bare gold surface is also less specific orientationwise. Interestingly, the bare gold surface bears no atomic charge and makes favorable interactions only through van der Waals attraction, while the SAM covered surface, with hydroxyl moieties on the head, displays a slightly negative surface.

We investigated this issue further by looking at the parts of the enzyme's surface forming contacts with the solid surfaces. In our analysis, $\beta$ GA residues are considered to be in contact with the surfaces when the distance between one of their heavy atoms and a surface atom (SAM or gold) is less than $5 \AA$. The cumulated contact frequencies for the six trajectories were mapped on the protein surface and are shown in Figure 4 (and 
Figure 4: Mapping the contact frequencies between $\beta G A$ and the gold surfaces on the protein surface; red: low frequency areas, blue: high frequency areas; two views with a rotation around the vertical axis. (a) (b) Contacts between $\beta G A$ and the SAM-covered gold surface, (c) (d) Contacts between $\beta G A$ and the bare gold surface.

(a)

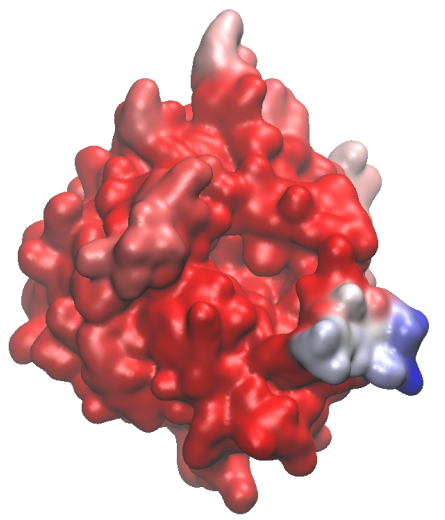

(c)

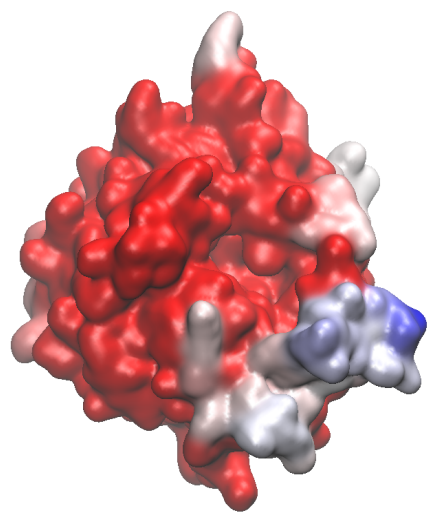

(b)

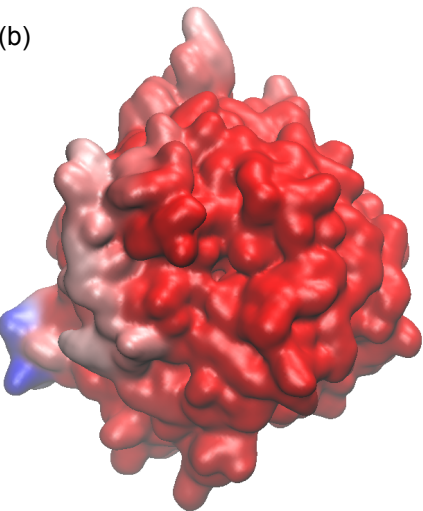

(d)

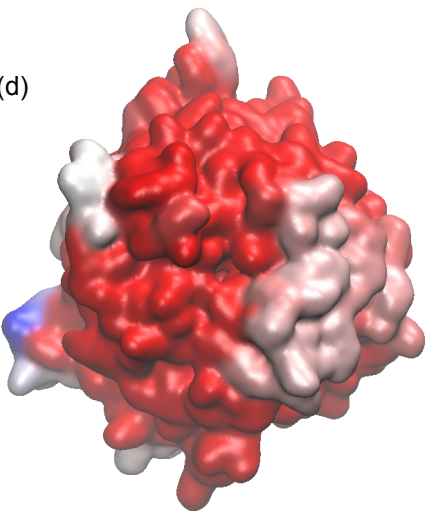

the average contact frequencies as a function of the residue number are available in Figure SI-6). $\beta$ GA binds both solid surfaces preferentially through residues Ala231, Asp232 and Glu233 (shown as a blue patch in Figure 4), which are located on the tip of an $\alpha$-helix protruding out of the enzyme globular shape. Note that this anchoring point corresponds to one of the most flexible parts of the protein (see Figure 6b), thus allowing the protein to present various orientations, even when it is surface bound. In addition, we can see in Figures $4 \mathrm{c}$ and $\mathrm{d}$ that the contacts formed between $\beta \mathrm{GA}$ and the bare gold layer seem to be less specific than with the SAM covered gold, as the binding patches are broader, and more widely distributed over the protein surface. In particular, 
one can observe an additional binding site on the opposite side of the enzyme that seems to be specific to the protein-bare gold interaction.

\section{Conformational stability}

The enzyme overall structure remains stable during all the trajectories, both for the bulk and confined simulations, with a backbone RMSD comprised between 1 and $2 \AA$ (see Figures $5 \mathrm{a}$ and $\mathrm{b}$ ). Besides, the protein central $\beta$-barrel structure is strongly conserved, and most conformational changes occur within the enzyme's outer shell, as can be seen in Figures 5c-f. Only two confined trajectories lead to a noticeable increase of the protein RMSD with regard to the bulk simulation, namely x90 and x180 (which are respectively shown in green and orange in Figure 5). In both cases $\beta$ GA adsorbs on the bare gold surface. For the $\mathrm{x} 90$ trajectory, the interaction with the bare gold surface is particularly strong, as it will even lead to a slight deformation of the protein core (see Figure 5d). The larger RMSD values obtained for the bare gold-bound enzyme compared to the SAM-bound enzyme are in agreement with earlier results obtained by Peng et al. ${ }^{63}$ when modeling the adsorption of cytochrome $c$ on similar surfaces. In addition, we calculated the enzyme radius of gyration $(\mathrm{Rg})$, which is also very stable, as it remains in the [21.0-21.6] $\AA$ range for all simulations. The density distributions (shown in Figure SI-7) are slightly broader for trajectories x90 and x180 (where the enzyme binds to the bare gold surface), and the protein deformations seem to lead to a more compact state, as the $\mathrm{Rg}$ distribution is shifted toward smaller values. Inversely, trajectories where $\beta \mathrm{GA}$ remains adsorbed on the SAM layer ( $\mathrm{z} 0$ and $\mathrm{x} 0$ ) or ends up in an unbound state (x270) present $\mathrm{Rg}$ distributions closer to the one obtained for the bulk simulation. 
Figure 5: Backbone RMSDs as a function of time, for the whole protein structure (a) $\beta G A$ in solution (b) confined $\beta G A$ trajectories; for the central $\beta$-barrel only (c) $\beta G A$ in solution (d) confined $\beta G A$ trajectories; for the outer shell only (e) $\beta G A$ in solution (f) confined $\beta G A$ trajectories.
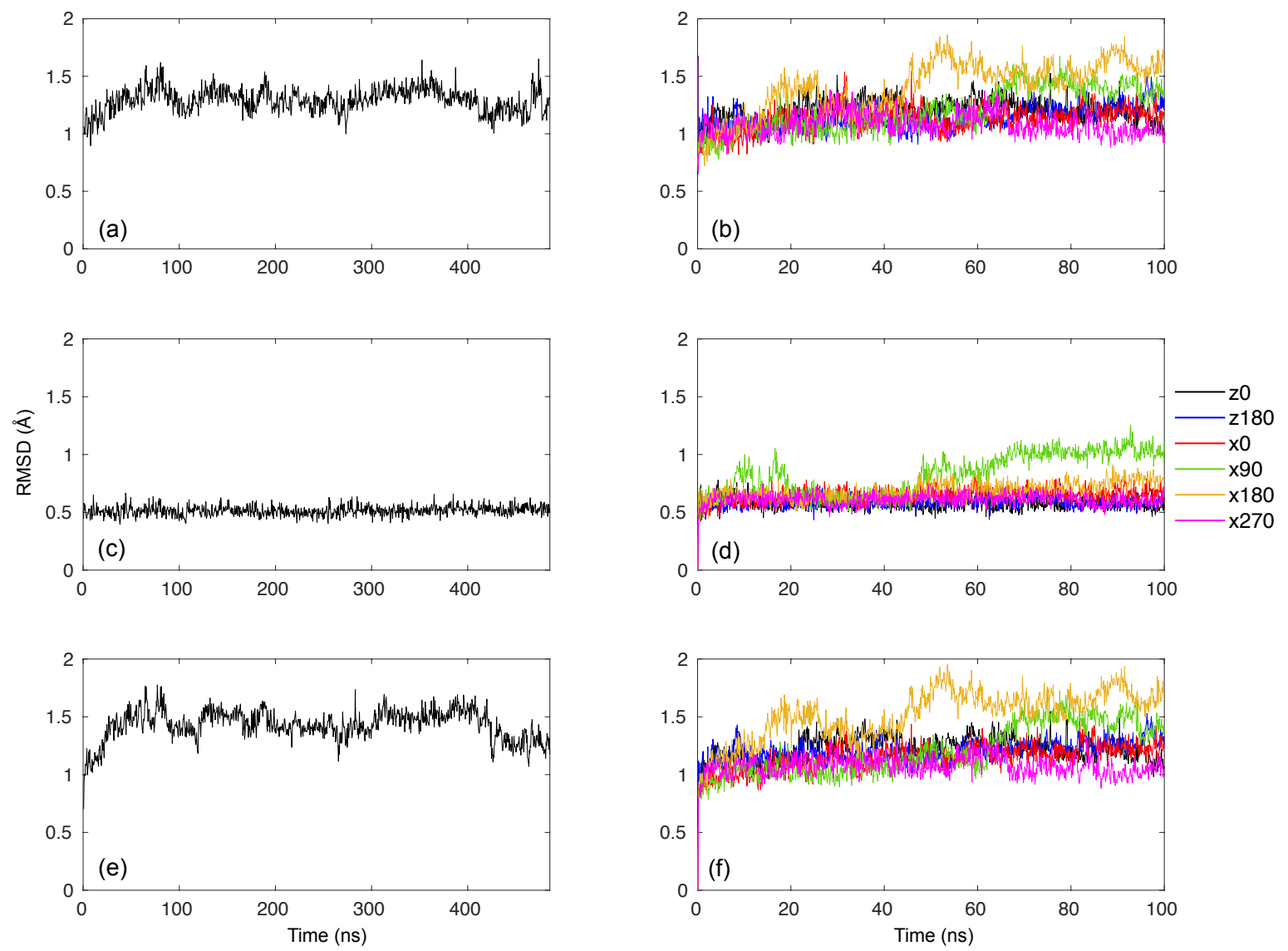

\section{Mechanical properties of the $\beta$-Glucosidase}

In the bulk trajectory The enzyme has a TIM-barrel fold, with a central $\beta$-barrel (shown in red in Figure 6a) surrounded by $\alpha$ helices (shown in green in Figure 6a). Its active site is located at the $\beta$-barrel entrance and comprises two catalytic glutamate residues, Glu166 and Glu35248 (shown as purple spheres in Figure 6a). The rigidity profile obtained for the bulk simulations is shown in Figure $6 \mathrm{~b}$ and reflects the protein regular structure, with a periodic array of rigidity peaks corresponding to each one of the central $\beta$-sheets that is characteristic of the TIM-barrel fold. 66 The peaks are separated by areas of low, oscillating force constants, that correspond to the external $\alpha$ helical residues. 
Figure 6: (a) Cartoon representation of $\beta G A$, with the central $\beta$-barrel shown in red and the external $\alpha$ helices in green. The two catalytic glutamates Glu166 and Glu352 are shown as purple van der Waals spheres. (b) Rigidity profile (in kcal.mol-1.A-2) for the $\beta G A$ in solution.

(a)

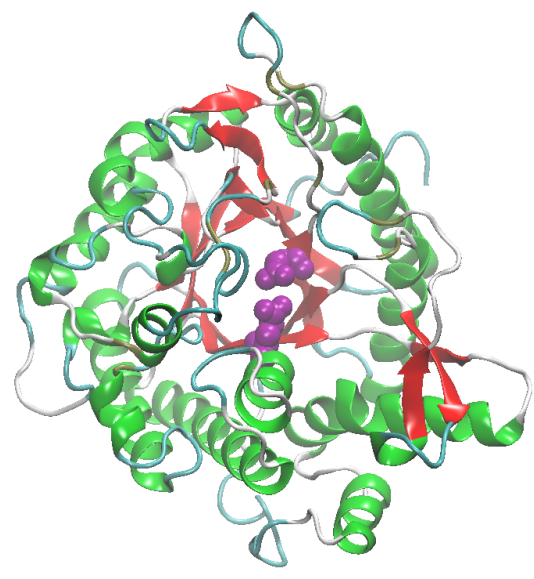

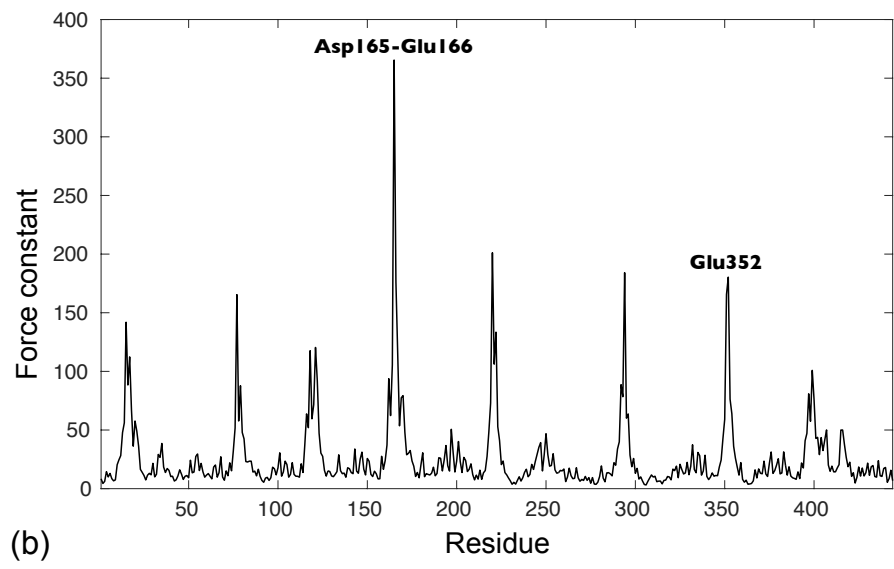

(b)

Both catalytic glutamates belong to highly rigid areas in the protein, a classic feature of catalytic residues in enzymes. ${ }^{85-86}$

Mechanical variations in the adsorbed $\beta$-Glucosidase We systematically compared the force constants obtained for the $13 \beta \mathrm{GA}$ representative structures from the confined trajectories and the force constants from the bulk trajectory. The resulting changes in the protein rigidity are shown in Figures 7 (subset of four structures) and SI-8 (all 13 structures). We observe important variations in $\beta \mathrm{GA}$ rigidity that are heterogeneously distributed along the protein sequence. The residues displaying the most important mechanical changes (which can be an increase or a decrease in their force constant) are originally rigid residues from the central $\beta$-sheets. This observation concerns in particular Glu166 and Glu352, and two other residues (Asn294 and Tyr296) that also belong to the catalytic site. One should note that these important mechanical variations take place even though the central $\beta$-barrel only undergoes minor conformational changes during the simulations. 


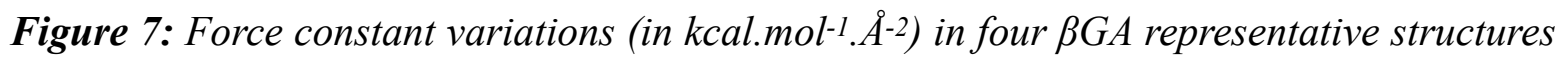
from the confined trajectories compared to the reference bulk structure. Trajectories: (a) $x 270$ (b) z180 (c) $x 900$ (d) $x 180$.
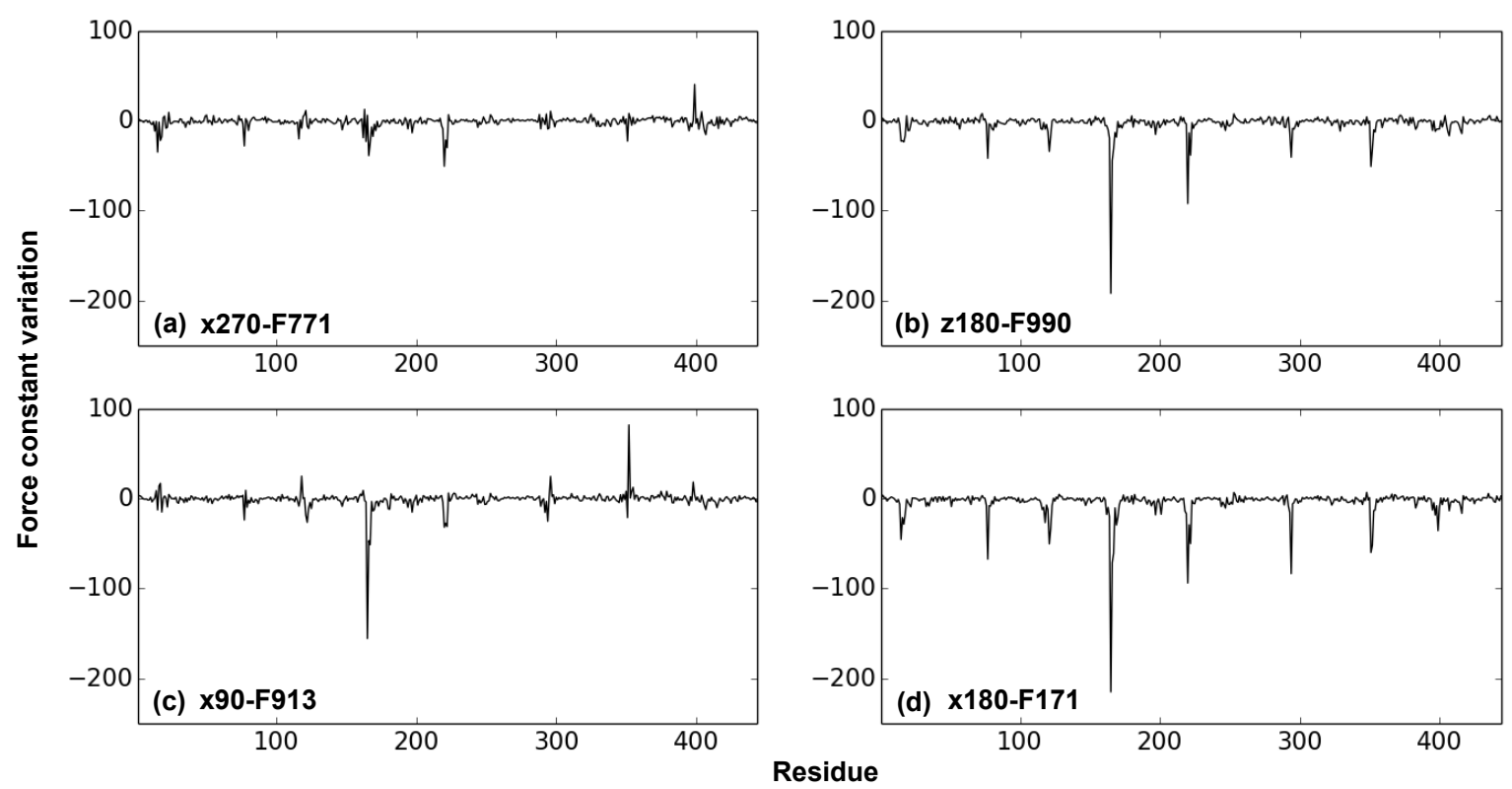

The mechanical changes in $\beta \mathrm{GA}$ can also be related to its adsorption behavior during the MD simulations. For example, during trajectory $x 270, \beta G A$ will detach itself from the SAM functionnalized surface after $50 \mathrm{~ns}$, and will spend the rest of the simulation without forming new contacts with either surface. In Figure 7a, we can see how the selected structure (corresponding to frame 771 , that is for $77 \mathrm{~ns}$ of simulation) only displays minor mechanical variations. On the other hand, structures corresponding to the adsorbed enzyme, either on the SAM or on the bare gold surface, present large mechanical changes. Interestingly, it seems that the mechanical impact of adsorption might also be linked to the adsorbing surface. Frames z180F990, x90F913 and $\mathrm{x} 180 \mathrm{~F} 171$ correspond to structures of $\beta \mathrm{GA}$ adsorbed on the bare gold surface, and they also present the most important rigidity loss for catalytic residue Glu166 (see Figures 7b-d). This flexibilization of the catalytic center might be detrimental to the enzyme function. 
Depending on the protein position between the two solid surfaces (see Figure SI-3 for a global view), the 13 representative structures extracted from the confined trajectories can be classified as unbound (structures z0F118, x90F265, x180F62 and x270F771), SAM-bound (z0F118, z0F461, z180F19, z180F186 and x0F270) or gold-bound (z180F990, x90F913, x180F171 and x180F797). While the average force constant in the unbound and SAM-bound structures remains very close to what was observed in the reference structure from the bulk simulations (with values of 25.5, 25.6 and 25.7 kcal.mol-1 $\AA^{-2}$ respectively), the gold-bound structures present a reduced average force constant of $23.5 \mathrm{kcal} . \mathrm{mol}^{-1} . \AA^{-2}$. Interestingly, this increase in the protein flexibility when adsorbed on a bare gold surface compared to the SAM-covered surface was also observed in an earlier modeling study on cytochrome $c,{ }^{63}$ and again, this perturbation of the enzyme mechanics is likely to impact its catalytic activity.

\section{Conclusions}

Understanding the interaction of enzymes with solid surfaces is a central issue in the biomaterials field. Here, we developed a multi-scale approach, based on all-atom Molecular Dynamics and coarse-grain Brownian Dynamics simulations, to investigate the binding of $\beta$-Glucosidase A on two solid surfaces: a bare gold surface and a SAM$\mathrm{OH}$ functionalized gold surface. We performed six $100 \mathrm{~ns}$ simulations using different starting orientations for $\beta$ GA. While these trajectories are too short to establish a representative sampling of the confined enzyme orientational and conformational landscape, as they only describe the early stage of adsorption, their analysis enable us to highlight a different behavior for $\beta \mathrm{GA}$ on the SAM-OH and on the bare gold surfaces. All the MD trajectories start with the enzyme located near the SAM-OH surface, the 
protein will desorb from the SAM in four cases out of six, and in three cases it will permanently bind to the bare gold surface. Looking at the protein/surface interaction energies, we can see that the interaction of $\beta$ GA with the bare gold surface is indeed much stronger (by a factor of 4) than with the SAM-OH surface. But this increase in stability goes with a loss of specificity in the bound-enzyme orientation, as the binding spots for $\beta \mathrm{GA}$ on bare gold are distributed all over the protein surface. While adsorption on both surfaces seems to have little impact on the protein conformation, our coarsegrain study of the enzyme shows that it is nonetheless sufficient to induce noticeable changes into its mechanical properties. In particular, adsorption on the bare gold surface leads to an important decrease in the rigidity of catalytic site residues, which might in turn lead to a reduced enzyme activity. One should also note that in the case of $\beta G A$, the broad size of the catalytic site, ${ }^{48,87}$ which is located at the entrance of the central $\beta$ barrel, and its structural stability ensure that it remains open at all times. However, many proteins comprise a buried active site that is connected to the surface through internal tunnels and cavities (like globins ${ }^{88}$ or hydrogenases ${ }^{38}$ ). In that case, one should also specifically investigate how the adsorption process might impact the tunnels width and topology, as a disrupted network is likely to perturb the access to the active site and the enzyme's catalytic activity.

Altogether, our results show that the efficient immobilization of enzymes on surfaces remains a complex issue. When designing an enzyme-based device, one must find an acceptable trade-off between stability and activity, as was recently illustrated by the experimental work of Weltz et al. ${ }^{89}$ In this perspective, molecular modeling tools have a lot to offer, since they permit to simultaneously retrieve information regarding both the immobilized enzyme structural stability and its function. 
Supporting Information: Surface electrostatic potential of $\beta G A$, representative structures used for the coarse-grain mechanical calculations, interaction energy between $\beta \mathrm{GA}$ and the solid surfaces, dipole moment orientation along time, $\beta \mathrm{GA}$ radius of gyration, technical note on the gold force-field parameters choice.

Acknowledgments: This work was supported by the ANR (ENZYMOR-ANR-16CE05-0024) and by the "Initiative d'Excellence" program from the French State (Grant "DYNAMO", ANR-11-LABX-0011-01). Simulations were performed using the HPC resources from $\mathrm{LBT} / \mathrm{HPC}$. 


\section{References}

1. Klibanov, A. M., Enzyme stabilization by immobilization. Anal. Biochem. 1979, 93 (1), 1-25.

2. Klibanov, A. M., Approaches to enzyme stabilization. Biochem. Soc. Trans. 1983, 11 (1), 19-20.

3. Willner, I.; Willner, B., Biomolecule-based nanomaterials and nanostructures. Nano Lett 2010, $10(10), 3805-15$.

4. Ansari, S. A.; Husain, Q., Potential applications of enzymes immobilized on/in nano materials: A review. Biotechnol Adv 2012, 30 (3), 512-23.

5. Bhakta, S. A.; Evans, E.; Benavidez, T. E.; Garcia, C. D., Protein adsorption onto nanomaterials for the development of biosensors and analytical devices: a review. Anal. Chim. Acta 2015, 872, 7-25.

6. Duncan, B.; Le, N. D. B.; Alexander, C.; Gupta, A.; Yesilbag Tonga, G.; Yazdani, M.; Landis, R. F.; Wang, L. S.; Yan, B.; Burmaoglu, S.; Li, X.; Rotello, V. M., Sensing by Smell: Nanoparticle-Enzyme Sensors for Rapid and Sensitive Detection of Bacteria with Olfactory Output. ACS nano 2017, 11 (6), 5339-5343.

7. Sheldon, R. A.; van Pelt, S., Enzyme immobilisation in biocatalysis: why, what and how. Chem. Soc. Rev. 2013, 42 (15), 6223-35.

8. Hitaishi, V.; Clement, R.; Bourassin, N.; Baaden, M.; de Poulpiquet, A.; Sacquin-Mora, S.; Ciaccafava, A.; Lojou, E., Controlling Redox Enzyme Orientation at Planar Electrodes. Catalysts 2018, 8 (5), 192.

9. Olloqui-Sariego, J. L.; Calvente, J. J.; Andreu, R., Immobilizing redox enzymes at mesoporous and nanostructured electrodes. Current Opinion in Electrochemistry 2021, 26, 100658.

10. Kim, B. Y.; Rutka, J. T.; Chan, W. C., Nanomedicine. The New England journal of medicine 2010, 363 (25), 2434-43.

11. Nienhaus, K.; Wang, H.; Nienhaus, G. U., Nanoparticles for biomedical applications: exploring and exploiting molecular interactions at the nano-bio interface. Materials Today Advances 2020, 5 , 100036.

12. Oteri, F.; Ciaccafava, A.; de Poulpiquet, A.; Baaden, M.; Lojou, E.; Sacquin-Mora, S., The weak, fluctuating, dipole moment of membrane-bound hydrogenase from Aquifex aeolicus accounts for its adaptability to charged electrodes. Phys. Chem. Chem. Phys. 2014, 16 (23), 11318-22.

13. Xiao, X.; Xia, H. Q.; Wu, R.; Bai, L.; Yan, L.; Magner, E.; Cosnier, S.; Lojou, E.; Zhu, Z.; Liu, A., Tackling the Challenges of Enzymatic (Bio)Fuel Cells. Chem Rev 2019, 119 (16), 9509-9558.

14. Yan, X.; Tang, J.; Tanner, D.; Ulstrup, J.; Xiao, X., Direct Electrochemical Enzyme Electron Transfer on Electrodes Modified by Self-Assembled Molecular Monolayers. Catalysts 2020, 10 (12), 1458.

15. Beaufils, C.; Man, H.-M.; de Poulpiquet, A.; Mazurenko, I.; Lojou, E., From Enzyme Stability to Enzymatic Bioelectrode Stabilization Processes. Catalysts 2021, 11 (4), 497.

16. Camarero, J. A., Recent developments in the site-specific immobilization of proteins onto solid supports. Biopolymers 2008, 90 (3), 450-8.

17. Weetall, H. H., Preparation of immobilized proteins covalently coupled through silane coupling agents to inorganic supports. Appl. Biochem. Biotechnol. 1993, 41 (3), 157-88.

18. Houseman, B. T.; Gawalt, E. S.; Mrksich, M., Maleimide-Functionalized Self-Assembled Monolayers for the Preparation of Peptide and Carbohydrate Biochips. Langmuir 2003, 19 (5), $1522-1531$

19. Sapsford, K. E.; Algar, W. R.; Berti, L.; Gemmill, K. B.; Casey, B. J.; Oh, E.; Stewart, M. H.; Medintz, I. L., Functionalizing nanoparticles with biological molecules: developing chemistries that facilitate nanotechnology. Chem Rev 2013, 113 (3), 1904-2074.

20. Rabe, M.; Verdes, D.; Seeger, S., Understanding protein adsorption phenomena at solid surfaces. Adv. Colloid Interface Sci. 2011, 162 (1-2), 87-106.

21. Mulheran, P. A.; Connell, D. J.; Kubiak-Ossowska, K., Steering protein adsorption at charged surfaces: electric fields and ionic screening. Rsc Adv 2016, 6 (77), 73709-73716.

22. Kubiak-Ossowska, K.; Jachimska, B.; Al Qaraghuli, M.; Mulheran, P. A., Protein interactions with negatively charged inorganic surfaces. Current Opinion in Colloid \& Interface Science 2019, 41, 104-117.

23. Latour, R. A., Fundamental Principles of the Thermodynamics and Kinetics of Protein Adsorption to Material Surfaces. Colloids Surf B Biointerfaces 2020, 191, 110992.

24. Bellion, M.; Santen, L.; Mantz, H.; Haehl, H.; Quinn, A.; Nagel, A.; Gilow, C.; Weitenberg, C.; Schmitt, Y.; Jacobs, K., Protein adsorption on tailored substrates: long-range forces and conformational changes. Journal of Physics-Condensed Matter 2008, 20 (40).

25. Secundo, F., Conformational changes of enzymes upon immobilisation. Chem. Soc. Rev. 2013, $42(15), 6250-61$.

26. Marruecos, D. F.; Schwartz, D. K.; Kaar, J. L., Impact of surface interactions on protein conformation. Current Opinion in Colloid \& Interface Science 2018, 38, 45-55. 
27. Bourassin, N.; Baaden, M.; Lojou, E.; Sacquin-Mora, S., Implicit Modeling of the Impact of Adsorption on Solid Surfaces for Protein Mechanics and Activity with a Coarse-Grained Representation. $J$ Phys Chem B 2020, 124 (39), 8516-8523.

28. Jasensky, J.; Ferguson, K.; Baria, M.; Zou, X.; McGinnis, R.; Kaneshiro, A.; Badieyan, S.; Wei, S.; Marsh, E. N. G.; Chen, Z., Simultaneous Observation of the Orientation and Activity of SurfaceImmobilized Enzymes. Langmuir 2018, 34 (31), 9133-9140.

29. Zou, X.; Wei, S.; Badieyan, S.; Schroeder, M.; Jasensky, J.; Brooks, C. L., 3rd; Marsh, E. N. G.; Chen, Z., Investigating the Effect of Two-Point Surface Attachment on Enzyme Stability and Activity. $J$. Am. Chem. Soc. 2018, 140 (48), 16560-16569.

30. Wei, Y.; Thyparambil, A. A.; Wu, Y.; Latour, R. A., Adsorption-induced changes in ribonuclease A structure and enzymatic activity on solid surfaces. Langmuir 2014, 30 (49), 14849-58.

31. Hitaishi, V. P.; Mazurenko, I.; Harb, M.; Clement, R.; Taris, M.; Castano, S.; Duche, D.; Lecomte, S.; Ilbert, M.; de Poulpiquet, A.; Lojou, E., Electrostatic-Driven Activity, Loading, Dynamics, and Stability of a Redox Enzyme on Functionalized-Gold Electrodes for Bioelectrocatalysis. Acs Catalysis 2018, 8 (12), 12004-12014.

32. Zheng, H.; Yang, S. J.; Zheng, Y. C.; Cui, Y.; Zhang, Z.; Zhong, J. Y.; Zhou, J., Electrostatic Effect of Functional Surfaces on the Activity of Adsorbed Enzymes: Simulations and Experiments. ACS Appl Mater Interfaces 2020, 12 (31), 35676-35687.

33. Zanuso, E.; Gomes, D. G.; Ruiz, H. A.; Teixeira, J. A.; Domingues, L., Enzyme immobilization as a strategy towards efficient and sustainable lignocellulosic biomass conversion into chemicals and biofuels: current status and perspectives. Sustainable Energy \& Fuels 2021, 5 (17), 4233-4247.

34. Imam, H. T.; Marr, P. C.; Marr, A. C., Enzyme entrapment, biocatalyst immobilization without covalent attachment. Green Chemistry 2021, 23 (14), 4980-5005.

35. Rodrigues, R. C.; Berenguer-Murcia, A.; Carballares, D.; Morellon-Sterling, R.; FernandezLafuente, R., Stabilization of enzymes via immobilization: Multipoint covalent attachment and other stabilization strategies. Biotechnol Adv 2021, 52, 107821.

36. Zhang, A. J.; Xie, Y.; Zhou, J., Experimental Control and Characterization of Protein Orientation on Surfaces. Progress in Chemistry 2009, 21 (7-8), 1408-1417.

37. Rodriguez-Quijada, C.; Sanchez-Purra, M.; de Puig, H.; Hamad-Schifferli, K., Physical Properties of Biomolecules at the Nanomaterial Interface. J Phys Chem B 2018, 122 (11), 2827-2840. 38. Oteri, F.; Baaden, M.; Lojou, E.; Sacquin-Mora, S., Multiscale simulations give insight into the hydrogen in and out pathways of [NiFe]-hydrogenases from Aquifex aeolicus and Desulfovibrio fructosovorans. J Phys Chem B 2014, 118 (48), 13800-11.

39. Brancolini, G.; Tozzini, V., Multiscale modeling of proteins interaction with functionalized nanoparticles. Current Opinion in Colloid \& Interface Science 2019, 41, 66-73.

40. Malaspina, D. C.; Perez-Fuentes, L.; Drummond, C.; Bastos-Gonzalez, D.; Faraudo, J., Proteinsurface interactions at the nanoscale: Atomistic simulations with implicit solvent models. Current Opinion in Colloid \& Interface Science 2019, 41, 40-49.

41. Quan, X. B.; Liu, J.; Zhou, J., Multiscale modeling and simulations of protein adsorption: progresses and perspectives. Current Opinion in Colloid \& Interface Science 2019, 41, 74-85.

42. Latour, R. A., Molecular simulation of protein-surface interactions: benefits, problems, solutions, and future directions. Biointerphases 2008, 3 (3), FC2-12.

43. Ozboyaci, M.; Kokh, D. B.; Corni, S.; Wade, R. C., Modeling and simulation of protein-surface interactions: achievements and challenges. Q. Rev. Biophys. 2016, 49, e4.

44. Dasetty, S.; Meza-Morales, P. J.; Getman, R. B.; Sarupria, S., Simulations of interfacial processes: recent advances in force field development. Current Opinion in Chemical Engineering 2019, $23,138-145$.

45. Dutta, S.; Bellucci, L.; Agostini, M.; Gagliardi, M.; Corni, S.; Cecchini, M.; Brancolini, G., Atomistic simulations of gold surface functionalization for nanoscale biosensors applications. Nanotechnology 2020, 32 (9), 095702.

46. Ganazzoli, F.; Raffaini, G., Classical atomistic simulations of protein adsorption on carbon nanomaterials. Current Opinion in Colloid \& Interface Science 2019, 41, 11-26.

47. Brancolini, G.; Bellucci, L.; Maschio, M. C.; Di Felice, R.; Corni, S., The interaction of peptides and proteins with nanostructures surfaces: a challenge for nanoscience. Current Opinion in Colloid \& Interface Science 2019, 41, 86-94.

48. Jeng, W. Y.; Wang, N. C.; Lin, M. H.; Lin, C. T.; Liaw, Y. C.; Chang, W. J.; Liu, C. I.; Liang, P. H.; Wang, A. H., Structural and functional analysis of three beta-glucosidases from bacterium Clostridium cellulovorans, fungus Trichoderma reesei and termite Neotermes koshunensis. J Struct Biol 2011, 173 (1), 46-56.

49. $\quad$ Singhania, R. R.; Patel, A. K.; Sukumaran, R. K.; Larroche, C.; Pandey, A., Role and significance of beta-glucosidases in the hydrolysis of cellulose for bioethanol production. Bioresour. Technol. 2013, 127, 500-7. 
50. Karami, F.; Ghorbani, M.; Sadeghi Mahoonak, A.; Khodarahmi, R., Fast, inexpensive purification of $\beta$-glucosidase from Aspergillus niger and improved catalytic/physicochemical properties upon the enzyme immobilization: Possible broad prospects for industrial applications. LWT 2020, 118, 108770 .

51. Mahapatra, S.; Manian, R., Enhancement, production, and immobilization of beta-glucosidase from Zobellella denitrificans VIT SB117 and its utilization in bioethanol production from lignocellulosic feedstock. Biomass Conversion and Biorefinery 2020.

52. Huang, C.; Feng, Y.; Patel, G.; Xu, X. Q.; Qian, J.; Liu, Q.; Kai, G. Y., Production, immobilization and characterization of beta-glucosidase for application in cellulose degradation from a novel Aspergillus versicolor. Int J Biol Macromol 2021, 177, 437-446.

53. Morais Junior, W. G.; Pacheco, T. F.; Gao, S.; Martins, P. A.; Guisán, J. M.; Caetano, N. S., Sugarcane Bagasse Saccharification by Enzymatic Hydrolysis Using Endocellulase and $\beta$-glucosidase Immobilized on Different Supports. Catalysts 2021, 11 (3), 340.

54. Case, D. A.; Pearlman, D. A.; Caldwell, J. W.; Cheatham, T. E. r.; Rose, W. S.; Simmerling, C. L.; Darden, T. A.; Merz, K. M.; Stanton, R. V.; Cheng, A. L.; Vincent, J. J.; Crowley, M.; Tsui, V.; Radmer, R. J.; Duan, Y.; Pitera, J.; Massova, I.; Seibel, G. L.; Singh, U. C.; Weiner, P. K.; Kollman, P. A. AMBER 6, University of California, San Francisco: 1999.

55. Case, D. A. B., R. M.; Cerutti, D. S.; Cheatham, T. E.; Darden, T. A.; Duke, R. E.; Giese, T. J.; Gohlke, H.; Goetz, A. W.; Homeyer, N.; Izadi, S.; Janowski, P.; Kaus, J.; Kovalenko, A.; Lee, T. S.;

LeGrand, S.; Li, P.; Lin, C.; Luchko, T.; Luo, R.; Madej, B.; Mermelstein, D.; Merz, K. M.; Monard, G.; Nguyen, H.; Nguyen, H. T.; Omelyan, I.; Onufriev, A.; Roe, D. R.; Roitberg, A.; Sagui, C.; Simmerling, C. L.; Botello-Smith, W. M.; Swails, J.; Walker, R. C.; Wang, J.; Wolf, R. M.; Wu, X.; Xiao, L.; Kollman, P. A. AMBER 2016, University of California, San Francisco, 2016.

56. Nam, K.; Gao, J.; York, D. M., An Efficient Linear-Scaling Ewald Method for Long-Range Electrostatic Interactions in Combined QM/MM Calculations. Journal of Chemical Theory and Computation 2005, 1 (1), 2-13.

57. Felder, C. E.; Prilusky, J.; Silman, I.; Sussman, J. L., A server and database for dipole moments of proteins. Nucleic Acids Res. 2007, 35 (Web Server issue), W512-21.

58. $\quad$ Yang, S.; Liu, J.; Quan, X.; Zhou, J., Bilirubin Oxidase Adsorption onto Charged SelfAssembled Monolayers: Insights from Multiscale Simulations. Langmuir 2018, 34 (33), 9818-9828. 59. Ktari, N.; Fourati, N.; Zerrouki, C.; Ruan, M.; Seydou, M.; Barbaut, F.; Nal, F.; Yaakoubi, N.; Chehimi, M. M.; Kalfat, R., Design of a polypyrrole MIP-SAW sensor for selective detection of flumequine in aqueous media. Correlation between experimental results and DFT calculations. $R s c A d v$ 2015, 5 (108), 88666-88674.

60. $\quad$ Ruan, M.; Seydou, M.; Noel, V.; Piro, B.; Maurel, F.; Barbault, F., Molecular Dynamics Simulation of a RNA Aptasensor. J Phys Chem B 2017, 121 (16), 4071-4080.

61. Onufriev, A. V.; Izadi, S., Water models for biomolecular simulations. WIREs Computational Molecular Science 2018, 8 (2), e1347.

62. Maier, J. A.; Martinez, C.; Kasavajhala, K.; Wickstrom, L.; Hauser, K. E.; Simmerling, C., ff14SB: Improving the Accuracy of Protein Side Chain and Backbone Parameters from ff99SB. Journal of Chemical Theory and Computation 2015, 11 (8), 3696-3713.

63. Peng, C.; Liu, J.; Zhou, J., Molecular Simulations of Cytochrome c Adsorption on a Bare Gold Surface: Insights for the Hindrance of Electron Transfer. The Journal of Physical Chemistry C 2015, 119 (35), 20773-20781.

64. Van der Spoel, D.; Lindahl, E.; Hess, B.; Groenhof, G.; Mark, A. E.; Berendsen, H. J. C., GROMACS: Fast, flexible, and free. J. Comp. Chem. 2005, 26 (16), 1701-1718.

65. Sacquin-Mora, S., Motions and mechanics: investigating conformational transitions in multidomain proteins with coarse-grain simulations. Mol. Simul. 2014, 40 (1-3), 229-236.

66. Sacquin-Mora, S., Bridging Enzymatic Structure Function via Mechanics: A Coarse-Grain Approach. Methods in Enzymology 2016, 578, 227-48.

67. Sacquin-Mora, S., Mechanical variations in proteins with large-scale motions highlight the formation of structural locks. J Struct Biol 2018, 203 (3), 195-204.

68. Tozzini, V., Coarse-grained models for proteins. Curr. Opin. Struct. Biol. 2005, 15 (2), 144-50.

69. Zacharias, M., Protein-protein docking with a reduced protein model accounting for side-chain flexibility. Protein Sci. 2003, 12 (6), 1271-82.

70. Ermak, D. L.; McCammon, J. A., Brownian dynamics with hydrodynamic interactions. J. Chem. Phys. 1978, 69, 1352-1360.

71. Pastor, R. W.; Venable, R.; Karplus, M., Brownian dynamics simulation of a lipid chain in a membrane bilayer. J. Chem. Phys. 1988, 89, 1112-1127.

72. $\quad$ Phillips, J. C.; Hardy, D. J.; Maia, J. D. C.; Stone, J. E.; Ribeiro, J. V.; Bernardi, R. C.; Buch, R.; Fiorin, G.; Henin, J.; Jiang, W.; McGreevy, R.; Melo, M. C. R.; Radak, B. K.; Skeel, R. D.; Singharoy, A.; Wang, Y.; Roux, B.; Aksimentiev, A.; Luthey-Schulten, Z.; Kale, L. V.; Schulten, K.; Chipot, C.; 
Tajkhorshid, E., Scalable molecular dynamics on CPU and GPU architectures with NAMD. J. Chem. Phys. 2020, 153 (4), 044130.

73. Liu, J.; Yu, G.; Zhou, J., Ribonuclease A adsorption onto charged self-assembled monolayers: A multiscale simulation study. Chem. Eng. Sci. 2015, 121, 331-339.

74. Hoefling, M.; Monti, S.; Corni, S.; Gottschalk, K. E., Interaction of beta-sheet folds with a gold surface. PLoS One 2011, 6 (6), e20925.

75. Gopalakrishnan, R.; Azhagiya Singam, E. R.; Vijaya Sundar, J.; Subramanian, V., Interaction of collagen like peptides with gold nanosurfaces: a molecular dynamics investigation. Phys. Chem. Chem. Phys. 2015, 17 (7), 5172-5186.

76. Alsharif, S. A.; Power, D.; Rouse, I.; Lobaskin, V., In Silico Prediction of Protein Adsorption Energy on Titanium Dioxide and Gold Nanoparticles. Nanomaterials (Basel) 2020, 10 (10). 77. $\quad$ MacKerell, A. D.; Bashford, D.; Bellott, M.; Dunbrack, R. L.; Evanseck, J. D.; Field, M. J.; Fischer, S.; Gao, J.; Guo, H.; Ha, S.; Joseph-McCarthy, D.; Kuchnir, L.; Kuczera, K.; Lau, F. T. K.; Mattos, C.; Michnick, S.; Ngo, T.; Nguyen, D. T.; Prodhom, B.; Reiher, W. E.; Roux, B.; Schlenkrich, M.; Smith, J. C.; Stote, R.; Straub, J.; Watanabe, M.; Wiórkiewicz-Kuczera, J.; Yin, D.; Karplus, M., AllAtom Empirical Potential for Molecular Modeling and Dynamics Studies of Proteins. The Journal of Physical Chemistry B 1998, 102 (18), 3586-3616.

78. Bjelkmar, P. r.; Larsson, P.; Cuendet, M. A.; Hess, B.; Lindahl, E., Implementation of the CHARMM Force Field in GROMACS: Analysis of Protein Stability Effects from Correction Maps, Virtual Interaction Sites, and Water Models. J. Chem. Theory Comput. 2010, 6 (2), 459-466.

79. Kaminski, G. A.; Friesner, R. A.; Tirado-Rives, J.; Jorgensen, W. L., Evaluation and reparametrization of the OPLS-AA force field for proteins via comparison with accurate quantum chemical calculations on peptides. J. Phys. Chem. B 2001, 105, 6474-6487.

80. Kony, D.; Damm, W.; Stoll, S.; Van Gunsteren, W. F., An improved OPLS-AA force field for carbohydrates. J. Comput. Chem. 2002, 23 (15), 1416-1429.

81. Wright, L. B.; Rodger, P. M.; Corni, S.; Walsh, T. R., GolP-CHARMM: First-Principles Based Force Fields for the Interaction of Proteins with $\mathrm{Au}(111)$ and $\mathrm{Au}(100)$. J Chem Theory Comput 2013, 9 (3), 1616-30.

82. Lopez, H.; Lobaskin, V., Coarse-grained model of adsorption of blood plasma proteins onto nanoparticles. J. Chem. Phys. 2015, 143 (24), 243138.

83. Power, D.; Rouse, I.; Poggio, S.; Brandt, E.; Lopez, H.; Lyubartsev, A.; Lobaskin, V., A multiscale model of protein adsorption on a nanoparticle surface. Modelling and Simulation in Materials Science and Engineering 2019, 27 (8), 084003.

84. Anand, G.; Sharma, S.; Dutta, A. K.; Kumar, S. K.; Belfort, G., Conformational transitions of adsorbed proteins on surfaces of varying polarity. Langmuir 2010, 26 (13), 10803-11.

85. Yang, L. W.; Bahar, I., Coupling between catalytic site and collective dynamics: a requirement for mechanochemical activity of enzymes. Structure 2005, 13 (6), 893-904.

86. Sacquin-Mora, S.; Laforet, E.; Lavery, R., Locating the active sites of enzymes using mechanical properties. Proteins 2007, 67 (2), 350-9.

87. Sinha, S. K.; Das, S.; Konar, S.; Ghorai, P. K.; Das, R.; Datta, S., Elucidating the regulation of glucose tolerance in a beta-glucosidase from Halothermothrix orenii by active site pocket engineering and computational analysis. Int J Biol Macromol 2020, 156, 621-632.

88. Bocahut, A.; Bernad, S.; Sebban, P.; Sacquin-Mora, S., Frontier residues lining globin internal cavities present specific mechanical properties. Journal of the American Chemical Society 2011, 133 (22), 8753-61.

89. Weltz, J. S.; Kienle, D. F.; Schwartz, D. K.; Kaar, J. L., Reduced Enzyme Dynamics upon Multipoint Covalent Immobilization Leads to Stability-Activity Trade-off. J. Am. Chem. Soc. 2020, 142 (7), 3463-3471. 
bioRxiv preprint doi: https://doi.org/10.1101/2021.07.02.450859; this version posted October 8, 2021. The copyright holder for this preprint (which was not certified by peer review) is the author/funder, who has granted bioRxiv a license to display the preprint in perpetuity. It is made available under aCC-BY-NC-ND 4.0 International license.

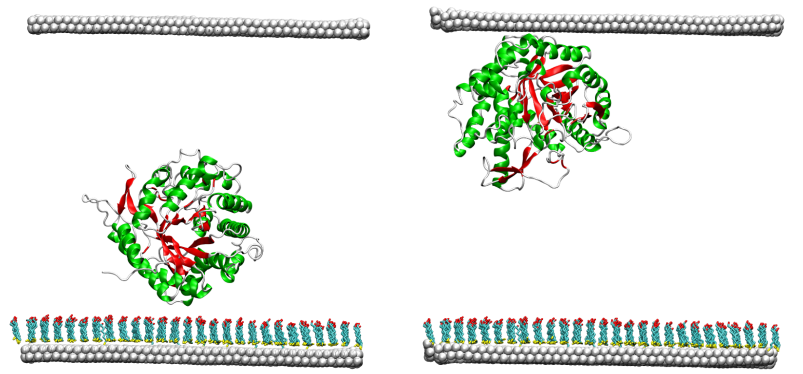

TOC image 